\title{
Low-Dose Triple Antihypertensive Combination Therapy in Patients with Hypertension: A Randomized, Double-Blind, Phase II Study [Corrigendum]
}

\section{Hong SJ, Sung KC, Lim SW, et al. Drug Des Devel Ther. 2020;14:5735-5746}

Page 5735, the affiliation for Ki-Chul Sung should be “2Department of Cardiology, Kangbuk Samsung Hospital, Sungkyunkwan University College of Medicine, Seoul, Republic of Korea".

Page 5744, Acknowledgment section, $4^{\text {th }}-6^{\text {th }}$ lines, “.... Hospital, Korea University College of Medicine), Ki- Chul
Sung (Gangbuk Samsung Hospital, Sungkyunkwan University College of Medicine), Sang-Wook Lim (CHA....." should read ".......Hospital, Korea University College of Medicine), Ki- Chul Sung (Kangbuk Samsung Hospital, Sungkyunkwan University College of Medicine), SangWook Lim (CHA......"

The authors apologize for these errors.

\section{Publish your work in this journal}

Drug Design, Development and Therapy is an international, peerreviewed open-access journal that spans the spectrum of drug design and development through to clinical applications. Clinical outcomes, patient safety, and programs for the development and effective, safe, and sustained use of medicines are a feature of the journal, which has also been accepted for indexing on PubMed Central. The manuscript management system is completely online and includes a very quick and fair peer-review system, which is all easy to use. Visit http://www. dovepress.com/testimonials.php to read real quotes from published authors. 